\title{
Occupational Exposures Among Hair and Nail Salon Workers: a Scoping Review
}

\author{
Lesliam Quiros-Alcala $^{1} \cdot$ Anna Z. Pollack ${ }^{2} \cdot$ Nedelina Tchangalova $^{3} \cdot$ Melissa DeSantiago $^{4} \cdot$ Lucy K. A. Kavi $^{5}$ \\ Published online: 21 September 2019 \\ (C) Springer Nature Switzerland AG 2019
}

\begin{abstract}
Purpose of Review To review the literature published from 2014 to 2019 on hair and nail salon workers concerning exposure assessment, reproductive and respiratory endpoints, and endocrine disruption, in relation to workplace exposures.

Recent Findings We identified 29 relevant peer-reviewed publications. Overall, there were insufficient studies to determine whether working in these settings is associated with reproductive health endpoints, although prior studies suggest that reproductive effects are of concern. There is consistent evidence that working in hair and nail salons may increase the risk of respiratory effects. Also, despite the fact that many hair and nail care products contain endocrine disrupting compounds, no recent studies have evaluated endocrine-related endpoints. Moreover, few studies have evaluated chemical exposures in these settings and biomonitoring studies are sparse.

Summary Improved exposure assessment of chemical hazards in hair and nail salons is necessary to properly characterize occupational exposures and assess their potential health risks. Further studies on endpoints related to endocrine disruption and reproductive health outcomes among hair and nail salon workers are needed. Improved exposure and epidemiologic studies will help inform chemical exposure mitigation efforts in a vulnerable occupational population, as well as policies related to workplace and consumer product safety.
\end{abstract}

Keywords Occupational exposures $\cdot$ Hair and nail salon workers $\cdot$ Hairdressers $\cdot$ Reproductive $\cdot$ Respiratory $\cdot$ Endocrine

\section{Introduction}

In the United States, the hair and nail salon industry employs approximately one million people, and over $90 \%$ of hair and

This article is part of the Topical Collection on Occupational Health

Electronic supplementary material The online version of this article (https://doi.org/10.1007/s40572-019-00247-3) contains supplementary material, which is available to authorized users.

Lesliam Quiros-Alcala

lalcala1@jhu.edu

Anna Z. Pollack

apollac2@gmu.edu

Nedelina Tchangalova

nedelina@umd.edu

Melissa DeSantiago

melissd@umd.edu

Lucy K. A. Kavi

1kavi@umd.edu nail salon workers are women, many of whom are of reproductive age [1]. It is estimated that $42 \%$ of nail salon workers are Asian immigrants [2•], while Black women and Latinas respectively comprise $14 \%$ and $18 \%$ of hair salon workers and
1 Department of Environmental Health and Engineering, Johns Hopkins Bloomberg School of Public Health, 615 N. Wolfe Street, Room E6616, Baltimore, MD 21205, USA

2 Department of Global and Community Health, George Mason University, 4400 University Drive, MS 5B7, Fairfax, VA 22030, USA

3 STEM library, University of Maryland, College Park, MD 20742, USA

4 School of Public Health, University of Maryland, College Park, MD 20742, USA

5 School of Public Health, Maryland Institute of Applied Environmental Health (MIAEH), University of Maryland, College Park, MD 20742, USA 
cosmetologists [1]. Hair and nail salon workers are continually exposed to multiple chemicals, including known and suspected carcinogens, reproductive toxicants, respiratory irritants, and endocrine disruptors $[3 \bullet, 4,5 \bullet \bullet, 6,7]$. Still, few US studies have evaluated chemical exposures in hair and nail salons. Additionally, the disproportionate composition of workers from marginalized groups in nail salons, and the use of potentially harmful ethnic hair products among hairdressers primarily serving a multicultural clientele, underscores the importance of evaluating occupational chemical exposures and associated health risks $[8 \bullet \bullet, 9]$.

Ingredients in products used in hair and nail salons include endocrine disrupting compounds (EDCs) like parabens and phthalates $\left[10^{\bullet}\right]$. EDCs can mimic or block endogenous endocrine function, with wide-ranging health implications, including reproductive effects [11]. Many of the chemicals contained, emitted or formed from the use of hair and nail products are also known or suspected respiratory irritants and sensitizing agents, including volatile organic compounds (VOCs) like formaldehyde in hair straighteners and nail polishes, ammonia in hair dyes, persulfates in bleaches, and phthalates added for fragrance or as solvents [12-15]. Several studies indicate that women in this occupational group may disproportionately suffer from adverse respiratory effects $[16,17]$, although some studies have not observed these associations [18•]. Inconsistent findings across epidemiologic studies on hair and nail salon workers may, in part, be due to the use of job title to assess workplace exposures as well as differences in products used, clientele served, and outcomes assessed.

Despite the potential increased risk of adverse effects among hair and nail salon workers, recent studies evaluating chemical exposures and health endpoints among individuals employed in the cosmetology industry are limited. In this review, we sought to synthesize the literature from the past 5 years on hair and nail salon worker exposures focusing on studies that evaluated reproductive, respiratory, and endocrine-related endpoints, as well as studies that assessed occupational chemical exposures using environmental or biological monitoring. We also reviewed current data gaps to inform future studies.

\section{Methods}

\section{Developing Key Terms and Search Strategy}

We followed the guidelines from the Centre for Reviews and Dissemination [19] and the Cochrane Handbook for Intervention Reviews to develop search terms and a search strategy [20]. Key search terms applicable to occupational and environmental health studies in hair and nail salons were guided by the Population, Exposure, and Outcome (PEO) framework as outlined below [21]:

- Population: hair and nail salon workers; given that these occupational workgroups consist of $>90 \%$ females, we focused on summarizing information on female workers of all ages, races, and ethnicities.

- Exposure: toxic salon products, indoor air pollution, and other occupational chemical-related exposures.

- Outcome: reproductive, respiratory, and endocrine disrupting-related endpoints among hair and nail salon workers.

We scanned database subject thesauri and studies identified through a Google Scholar search to compile a list of relevant key terms. We focused our search on epidemiologic, environmental monitoring, and biomonitoring studies in hair and nail salons. We generated a list of key terms for each concept (Appendix 1) and combined them with Boolean operators (AND, OR) [22]. The search strategy is presented in Appendix 2 and was checked for syntax errors against the Peer Review of Electronic Search Strategies Checklist [23].

\section{Data Selection, Extraction, and Management}

On February 21, 2019, the public health librarian (NT) conducted a search in 29 EBSCO databases, PubMed (U.S. National Library of Medicine), Web of Science (Clarivate Analytics), and Public Health (ProQuest) (Appendix 3). Peer-reviewed studies published from January 2014 February 2019 were included. The search results were imported into Zotero for title/abstract screening and duplicate records were removed. A trained research assistant (LKK) initially screened articles, and the principal investigators (LQA and AZP) conducted a final review of preliminary studies. We recorded the search process and findings from the literature using the Preferred Reporting Items for Systematic Reviews and Meta-Analyses (PRISMA) statement [24] as shown in Appendix 4. While some articles included both males and females, we focused on synthesizing results observed among females whenever possible and limited our search to studies published in English.

\section{Results}

Our searches yielded a total of 2176 records from 2014 to 2019. After removing duplicate titles and abstracts, 978 studies remained and were screened. The 29 studies meeting eligibility criteria were read in full and included in this summary. Both reviewers (LQA and AZP) agreed on the final full-text articles included in this review. 


\section{Environmental Exposures and Biomonitoring Studies}

\section{Hair Salons}

We identified five studies that measured indoor air quality and air concentrations of chemicals in hair salons, including VOCs, particulate matter (PM), and phthalates [3•, 15, 25-27]. A study by Nilsson et al. [15] focused on the physical and chemical characterization of particle emissions during simulated client sessions using a hair bleach marketed as "dust-free" and one without this labeling. Levels of particle emissions were evaluated to assess exposures among 12 hairdressers performing hair bleaching in a controlled environment. Particulate matter $(\mathrm{PM})<10 \mu \mathrm{m}$ was detected during hair bleaching when regular bleaching powder was prepared, while dust-free bleaching powder emitted particles $>10 \mu \mathrm{m}$. Persulfate exposure was lower with dust-free bleaching powder. Another study by Saraga et al. [25] measured respirable particulate matter or RPM (i.e., suspended particle fraction with aerodynamic diameter $<4 \mu \mathrm{m}$ ) in the breathing zone of Greek volunteers, including two hairdressers and eight customers in a hair salon. A hairdresser using hairspray and a hairdryer was exposed to the highest levels of RPM $\left(286 \mu^{-3}\right)$.

Subedi et al. [26] measured phthalate dust concentrations in five hair salons in Kentucky, Indiana, and Texas and in other locations, including 11 residences in five states and 11 childcare facilities in seven states. Estimated daily intake of phthalate and non-phthalate plasticizers via dust in hair salons was approximately three times higher than those estimated for residential environments. Among non-phthalate plasticizers, acetyl tri- $n$-butyl citrate (ATBC) and diisobutyl adipate were found at concentrations 3-10 times higher in salons compared to residences and childcare facilities. ATBC is used in cosmetics, food contact wrappings, and toys [28], and diisobutyl adipate is used as a fragrance ingredient, plasticizer, as an emollient in skin-conditioning agents, and as a solvent [29]. Another study by Chang et al. [3•] measured indoor air contaminants and assessed indoor air quality parameters in five hair salons in Taipei. Four of the five phthalates measured were detected in $>69 \%$ of samples. Dibutyl phthalate (DBP), diethyl phthalate (DEP), and di[2-ethylhexyl] phthalate (DEHP) were detected in $97-100 \%$ of samples. The authors reported higher phthalate, isopropanol, butyl acetate, and ethyl acetate concentrations than previously reported in residences. For formaldehyde, $83 \%$ (25/30) of the samples exceeded the Taiwan Environmental Protection Agency's Indoor Air Quality (IAQ) standard of $98.4 \mu \mathrm{g} / \mathrm{m}^{3}$ and the National Institute of Occupational Safety and Health Recommended Exposure Limit (NIOSH REL) of $19.68 \mu \mathrm{g} / \mathrm{m}^{3}$. The number of workers, number of perming treatments, and frequency of formaldehyde-releasing product use was linked to indoor formaldehyde air concentrations. Additionally, some $\mathrm{CO}_{2}$ readings exceeded guidelines by the American Society of Heating, Refrigerating and Air-Conditioning Engineers (ASHRAE), and Taiwan's IAQ Act threshold (1000 ppm). Another study [27] conducted among 13 Palestinian hairdressers measured ammonia levels in hair salons. Researchers detected ammonia in all salons; ammonia concentrations were positively correlated with the size of the salon, number of salon workers, and number of customers served.

We identified two studies that conducted biomonitoring among hairdressers. One study [30] measured resorcinol in urine samples across different occupational groups, including hairdressers. Resorcinol is a synthetic chemical used in cosmetics, including permanent hair dyes where it reacts with a developer (e.g., peroxide) to bond the dye to the hair. Researchers compared urinary resorcinol concentrations between occupationally exposed groups. Hairdressers $(n=77)$ provided three spot urine samples: (1) a first morning-void sample after at least 1 day off from working in the salon, (2) a post-shift sample immediately after a work shift, and (3) a next-morning (first morning-void) sample. Urinary concentrations of resorcinol were higher in post-shift samples and similar between hairdressers and controls $(n=101)$. These findings warrant replication in other populations as product use patterns and ingredients may differ across populations and geographic regions. The other biomonitoring study identified quantified phthalate exposures among 68 Slovakian hairdressers and reported higher urinary phthalate biomarker concentrations among hairdressers compared to controls comprising of university students and staff $(n=32)[5 \cdot \bullet]$.

\section{Nail Salons}

Six studies [31-36] evaluated chemical exposures in nail salons through personal air monitoring, area air monitoring, biomonitoring, or a combination of these. One study conducted personal and area air monitoring of VOCs and carbon dioxide $\left(\mathrm{CO}_{2}\right)$ and measured IAQ parameters (e.g., air exchange rate, temperature, and relative humidity) at 17 Michigan salons [36]. Ethyl acetate and $n$-butyl acetate were detected in personal samples in all salons, while toluene, benzene, and formaldehyde were detected in some salons. Methyl methacrylate (MMA), a long-banned chemical, was identified in most salons. Personal VOC monitoring measurements exceeded area measurements, highlighting the importance of personal monitoring in these settings. Nail products were also tested for VOCs and identified ethyl acetate as the main component. Toluene was detected in nail polish and indoor air in eight of 17 salons. The initial threshold screening level, regulated by the Michigan Department of Environmental Quality, was exceeded for $12 \%$ of ethyl acetate and $50 \%$ of MMA measurements. Ventilation levels during the winter were low, although most salons met ASHRAE ventilation standards. 
In a Korean study among 50 nail salon workers from 30 salons, 13 VOCs were detected in personal air samples [34]. Several air samples had acetone, toluene, butyl acetate, and MMA levels exceeding Korean Occupational Exposure Limits. Almost all participants $(98 \%)$ worked without local exhaust ventilation, while $65 \%$ worked in salons with closed windows. Personal protective equipment (PPE) use was infrequent. Temperatures in salons ranged between 23.4 and $35.7{ }^{\circ} \mathrm{C}$, and the mean (SD) relative humidity was below ASHRAE guidelines [mean=55.7 (7.1)\%]. Chemical concentrations were higher in salons with general ventilation systems, suggesting that local exhaust may decrease personal exposure more effectively compared to general ventilation systems, which may pull chemicals into breathing zones.

Lamplugh et al. [33] measured VOCs (formaldehyde and BTEX - benzene, toluene, ethylbenzene, and xylenes) using area and personal monitors in six Colorado nail salons. Area monitoring was conducted over three weekdays and one weekend day for 8 hours each day. Formaldehyde concentrations in these salons ranged from 5 to $20 \mu \mathrm{g} / \mathrm{m}^{3}$ and exceeded the NIOSH REL $\left(19.6 \mu \mathrm{g} / \mathrm{m}^{3} ; 16 \mathrm{ppb}\right)$ in one salon. Researchers detected benzene, toluene, ethylbenzene, and xylenes in all salons, with toluene at the highest concentrations $\left(26.7-816 \mu \mathrm{g} / \mathrm{m}^{3}\right)$. Acetone, ethyl acetate, and $n$-butyl acetate were detected in personal samples in all salons. Despite being banned in Colorado, MMA was detected in two salons, highlighting the need for salon worker and owner education and discouraging the purchase of MMA-containing products [33]. A salon marketed as "non-toxic" had the highest levels of personal exposures to acetone, ethyl acetate, and $n$-butyl acetate, underscoring the importance of greater oversight on labeling and personal care product regulation.

A study of 109 Polish salons [32] measured VOC levels (ethanol, acetone, toluene, 2-propanol, 2-butanone, ethyl acetate, isopropyl acetate, $n$-butyl acetate) among 145 female nail salon workers and 145 healthy female volunteers employed in other occupations. Median area VOC levels in nail salons were all below Polish regulatory occupational limits. VOC concentrations were usually higher in the winter; however, seasonal variation may be driven by differences in the nail salons across seasons. Longer-term measurements would be informative since these findings reflect only short-term breathing zone measurements, which could underestimate true exposures. Pavilonis et al. [35] detected VOCs and $\mathrm{CO}_{2}$ in 10 New York city salons. The median total VOC (TVOC) concentration was $4.0 \mathrm{ppm}$ across salons, and concentrations were strongly correlated with $\mathrm{CO}_{2}(\mathrm{r}=0.81)$. Lastly, one study conducted short-term measurements of several IAQ parameters $\left(\mathrm{CO}_{2}\right.$, temperature, relative humidity, TVOCs, $\left.\mathrm{PM}_{2.5}\right)$ during working hours in 21 nail salons in Boston [31]. $\mathrm{CO}_{2}$ levels exceeded 800 ppm in 15 of 21 salons, suggesting that some salons may have inadequate ventilation. Higher TVOC and $\mathrm{PM}_{2.5}$ levels were observed in salons with less ventilation, and average TVOC, $\mathrm{CO}_{2}$, and $\mathrm{PM}_{2.5}$ levels were consistent within salons. Higher TVOC concentrations were also observed when tasks were being performed; however, these concentrations were not associated with the number of tasks being performed.

No studies within the last 5 years have evaluated biomarkers of exposure to chemicals that may affect the reproductive, respiratory, and endocrine systems among nail salon workers. In addition, biomonitoring studies beyond our 5-year scoping period are limited. Available evidence indicates that nail products contain reprotoxic and endocrine disrupting chemicals, and further studies are needed to adequately assess occupational exposures among these workers. Urinary biomonitoring in hair salon workers indicate feasibility of collecting biospecimens from nail salon workers and stress the importance of obtaining exposure estimates $[5 \bullet \bullet, 30]$.

\section{Reproductive Endpoints}

We identified four studies [37-40] on reproductive endpoints among hair or nail salon workers (Table 1). One study examined spontaneous abortion [38] utilizing Korean National Health Insurance records which covered $78 \%$ of all Korean births in 2013 and identified women by occupational status in relation to claims data. Employed women in any occupation were at greater risk of spontaneous abortion compared to nonworking women [38], and an increased odds of miscarriage was reported for the group comprising hair and nail salon workers. The two reference groups in the study included unemployed women and those employed in education.

Three studies examined birth outcomes [37, 39, 40]. In a record-based study conducted in Ibadan, Nigeria, female hairdressers had the highest proportion of infants with low Apgar scores at 5 minutes after birth of all occupations examined ( $n=1349)$ [37]. However, only bivariable relationships were examined and there was no adjustment for confounding. No associations between adverse birth outcomes and employment in cosmetology or as a manicurist were reported in a record linkage study in California, which included 81,205 births among cosmetologists and manicurists [39]. However, employment in cosmetology or as a manicurist was associated with increased risk of gestational diabetes and placenta previa [39]. Notably, when restricting analyses to Vietnamese participants, manicurists and cosmetologists had greater odds of small for gestational age births. In this study, researchers used two comparison groups: women employed as teachers, realtors, salespersons, office workers, and food service workers, and a separate comparison group of non-cosmetologists from the general population. This control selection approach can circumvent issues of healthy worker effect. A multisite French study [40] reported an elevated risk of hypospadias for children whose parents were occupationally exposed to EDCs, including hairdressers and beauticians ( $n=300$ with 


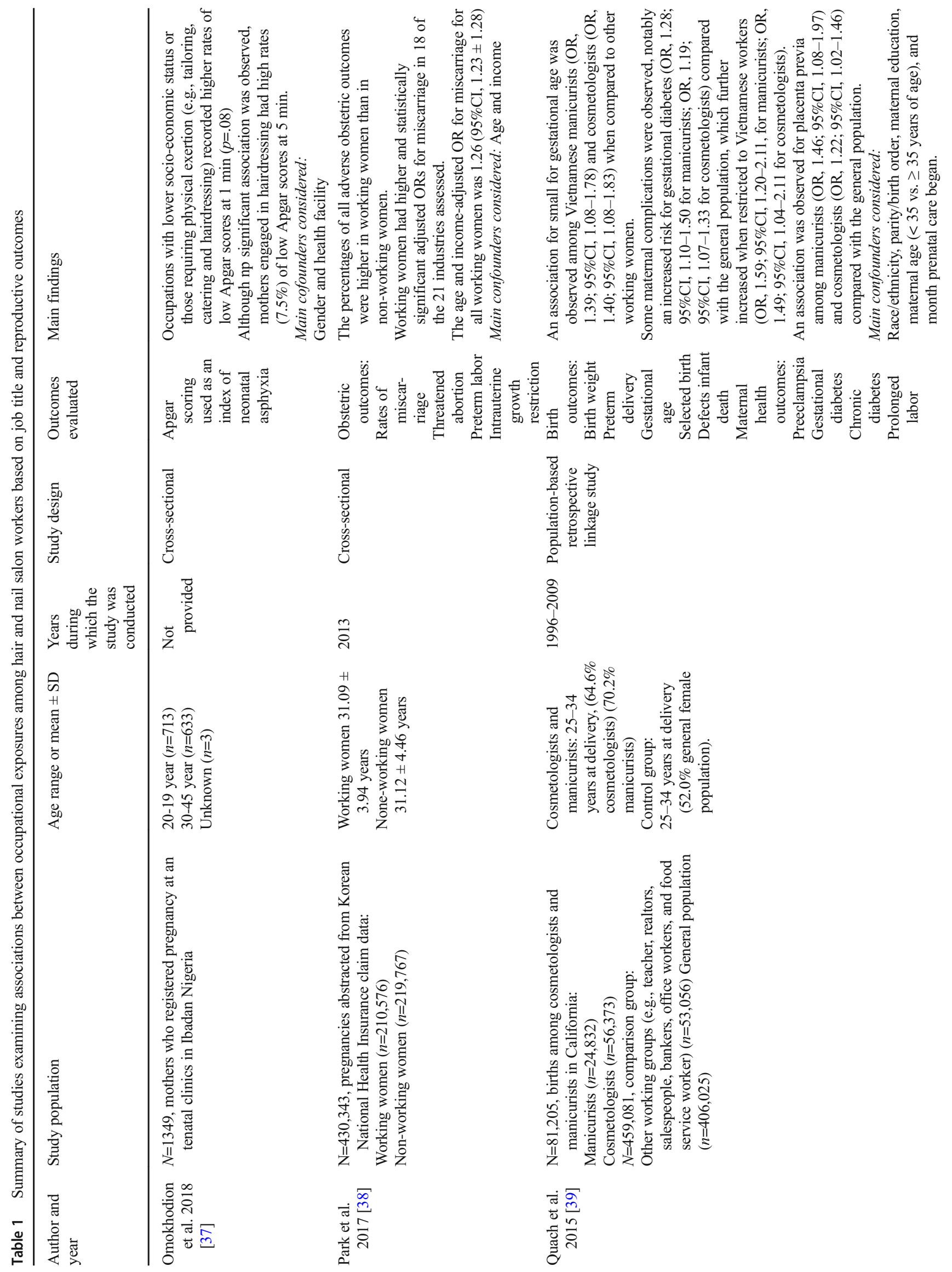




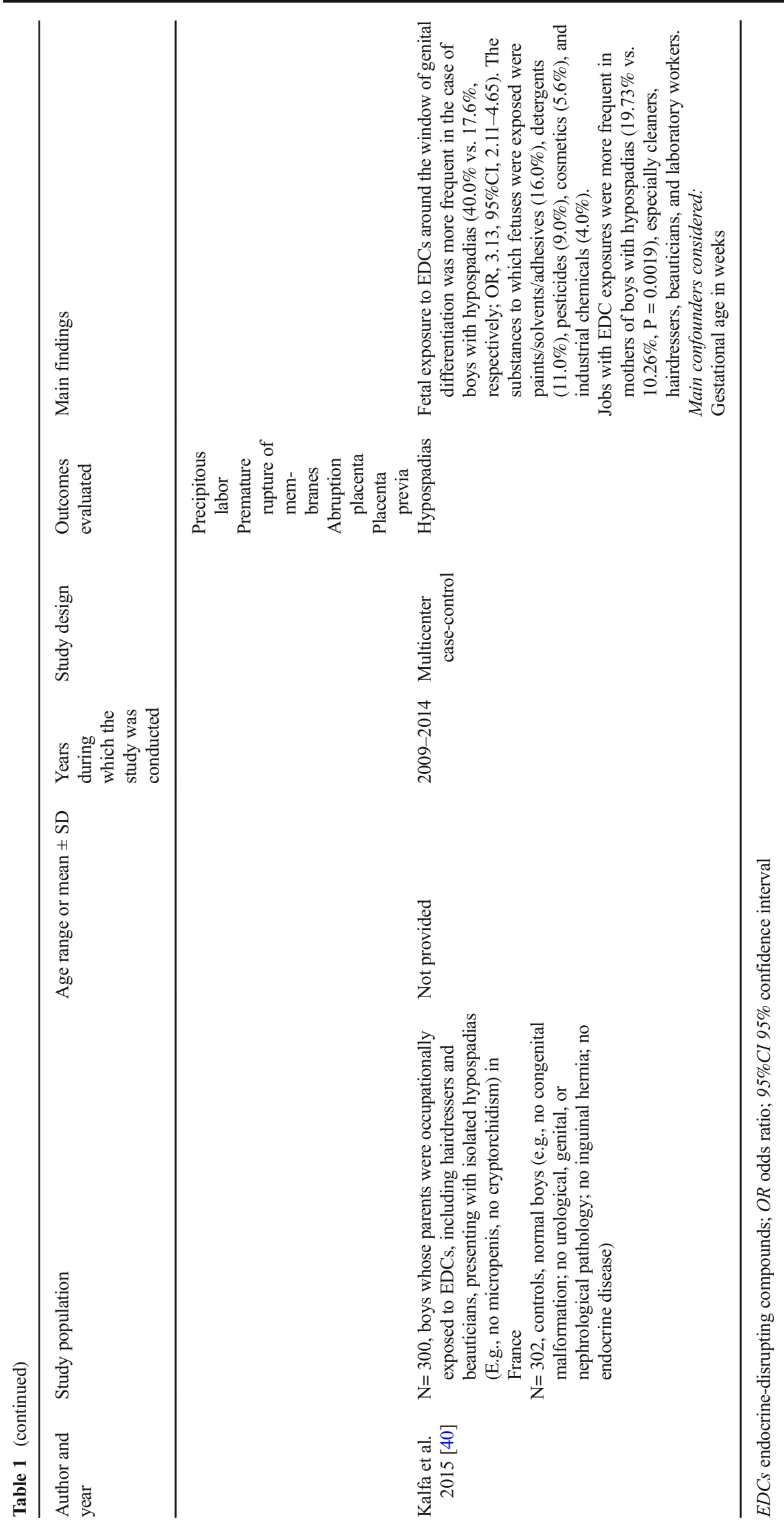


hypospadias, $n=302$ no malformation) [40]. Participants were free from genetic mutations that increased risk of hypospadias among offspring; parental occupation and an in-depth job exposure matrix was used to assess potential exposures to EDCs. Evaluation of the endpoint was a study strength, but the authors did not control for any potential confounders.

Select records-based studies reviewed were strengthened by the use of two comparison groups [38, 39]. These included women who do not work outside the home and those in education [38], as well as a broader range, comprising teachers, realtors, retail, office, and food service workers [39]. The inclusion of food service and retail workers in the comparison group aligns occupations of similar socioeconomic status, which may minimize selection bias. The potential for unemployed women to be more fecund than women in the workforce was another potential source of bias in select studies. This occurs because women with young children have lower employment rates [41]. Using alternate comparison groups is one approach to address this and is particularly important when information on parity and gravidity is unavailable. Ascertainment of outcomes of miscarriage and pregnancy loss was identified by health insurance records [38] or birth certificates [39]. For evaluating pregnancy loss, these sources are not ideal. Women with early pregnancy losses may not see a doctor, leading to missing data. This information bias may be non-differential but could result in bias in either direction [42]. Study limitations in the studies reviewed include lack of biomonitoring to confirm chemical exposures, small sample sizes, and lack of adjustment for important confounders, such as age. Future studies should consider modeling approaches that formulate analysis plans a priori and are not dependent on a statistical threshold. Given limited recent studies of reproductive outcomes and lack of cohesion across health endpoints, further research is necessary to determine if reproductive health endpoints are related to working in hair or nail salons.

\section{Respiratory Endpoints}

\section{Hairdressers}

We identified 10 articles [5••, 27, 43-50] related to respiratory outcomes (Table 2). Four studies assessed respiratory symptoms via questionnaires [43-46], while six additionally collected biospecimens and/or measures of lung function or inflammation [5••, 27, 47-50]. One study in New Zealand [47] reported an increased odds of self-reported chronic bronchitis symptoms among participants who had ever reported working as a hairdresser, although no associations with objective measures of lung function or chronic obstructive pulmonary disease (COPD) were observed. Lysdal et al. [46] reported higher prevalence of respiratory symptoms among hairdressers with adult asthma onset, as assessed by a mail-in questionnaire among 5239 Danish hairdressing school graduates. Twentyseven percent of respondents reported difficulty breathing or shortness of breath after contact with bleaching products. Other studies reported increased respiratory symptoms, including among hairdressers or hairdressing apprentices in Denmark [43, 44], Palestine [27, 49], Turkey [50], Sweden [48], and Egypt [45].

Several studies incorporated biospecimen collection and/or measures of lung function or inflammation [5••, 27, 47-50]. Diab et al. [48] studied Swedish hairdressers $(n=17)$ and two control groups ( $n=19$ asymptomatic hairdressers; $n=10$ females with pollen-driven rhinitis) for 30 days. Nasal reactivity to persulfate was evaluated via nasal lavage at work after $>2$ weeks of vacation. Hairdressers had increased nasal symptoms and eosinophil cationic protein, a marker of eosinophilic bronchial inflammation. Atopic hairdressers reported the most respiratory symptoms. Nemer et al. evaluated lung function over 5 years among 161 non-smoking female Palestinian hairdressers [49]. Hairdressers reported more respiratory symptoms and experienced decrements in lung function at the end of the follow-up period compared to baseline. Lung function was worse for hairdressers in salons with ammonia levels $>25$ ppm compared to hairdressers exposed to lower ammonia levels. In another study [27], the authors reported higher neutrophilic airway inflammation, as well as elevated exhaled nitric oxide (eNO) and blood C-reactive protein levels, a measure of systematic inflammation, among Palestinian hairdressers $(n=33)$ compared to controls $(n=35)$.

One study $[5 \bullet \cdot]$ applied biomonitoring to ascertain occupational exposures to select agents and examined associations with respiratory outcomes. Kolena et al. [5••] conducted a cross-sectional study among 68 Slovakian hairdressing apprentices (97\% female) to assess occupational phthalate exposures and associations with pulmonary function as compared to controls ( $n=32$ university students and staff; $66 \%$ female). Median phthalate metabolite concentrations were higher among hairdressing apprentices compared to controls. Greater phthalate metabolite concentrations were also inversely associated with select lung function measures, although the authors did not control for any potential confounders. Other limitations include the small sample size and inclusion of a higher proportion of male controls compared to hairdressers. Personal care products (PCPs) are a major source of phthalate exposure and PCP use is higher among females; to rule out the possibility that greater phthalate biomarker concentrations were due to personal care product use unrelated to occupational exposures, more female controls should have been included in the study [55].

In summary, several studies report an increased risk of adverse respiratory outcomes, including respiratory symptoms, lung function decrements, and inflammation among hairdressers from several countries. Some limitations noted in these recent studies include the cross-sectional design [5••, 


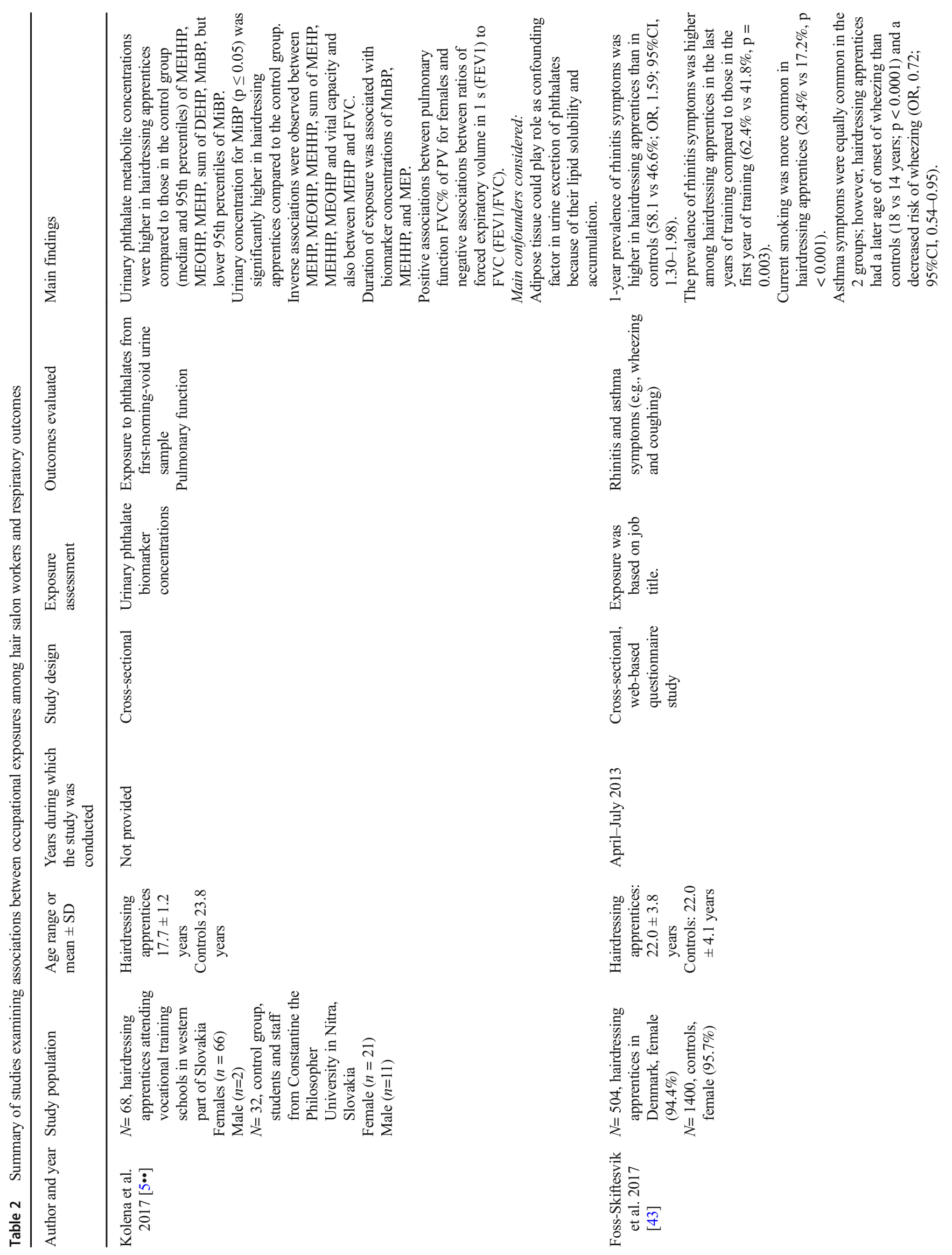




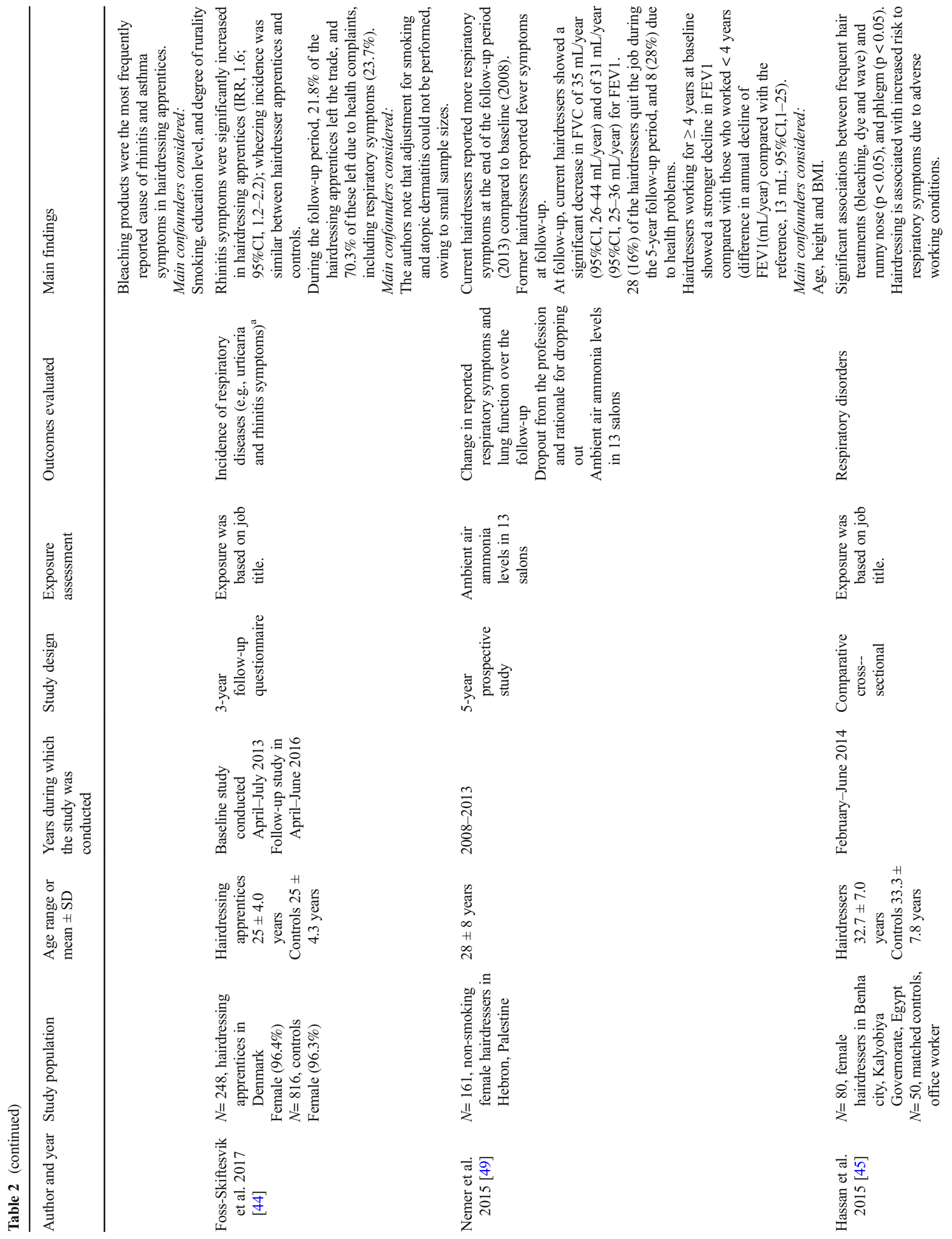




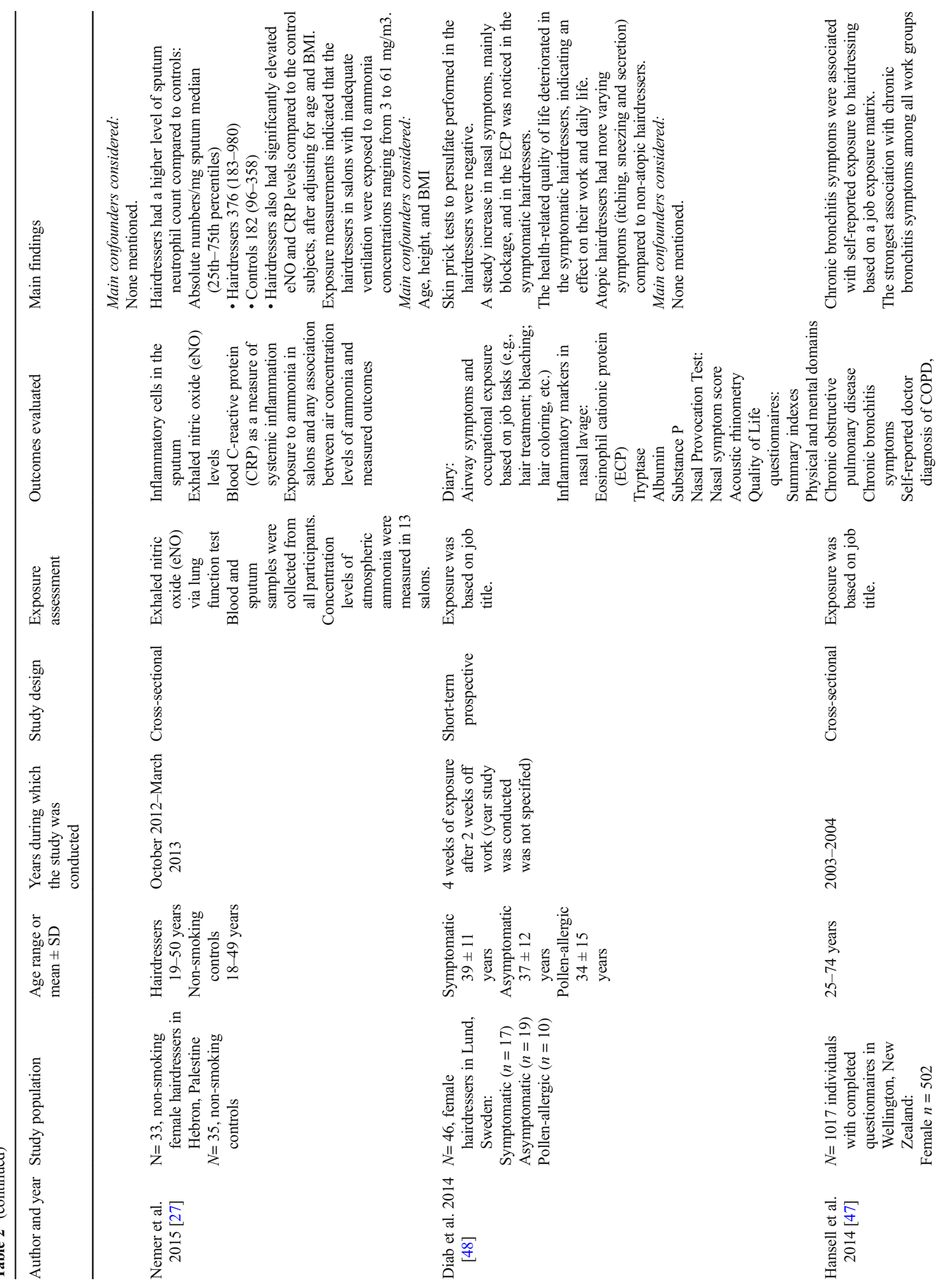




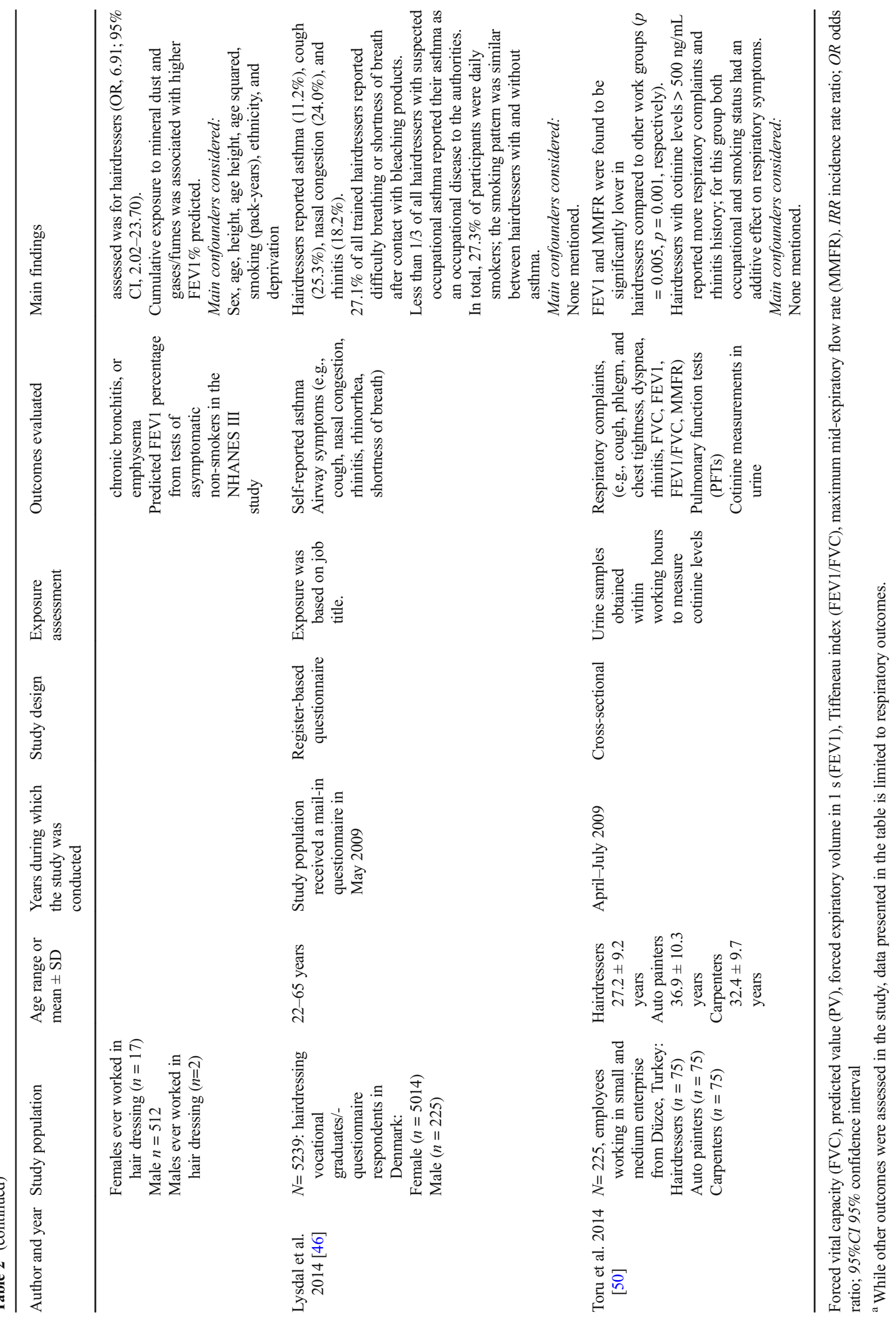


$27,43,45-47,50]$, sole reliance on questionnaires to ascertain respiratory outcomes [43-46], lack of biomonitoring to ascertain exposures and related health outcomes to specific contaminants $[27,43,45,47,48,50]$, lack of adjustment for critical confounders [44], small samples sizes [27, 47, 48], and potential bias arising from the healthy worker effect $[27,43-47,49$, 50]. Despite these limitations, studies generally arrived at similar conclusions.

\section{Nail Salon Workers}

Five articles [34, 51-54] assessed respiratory outcomes among nail salon workers (Table 3). One US study [54] surveyed 61 female Southeast Asian immigrant nail salon workers in Oregon. Allergies were among the most commonly reported problems, although a definition of allergies was not provided. Another cross-sectional study [51] of 68 workers from 40 nail salons in New Jersey reported frequent lung and throat irritation. Similarly, another study among 159 Korean nail salon technicians ( $98 \%$ female) from 120 salons reported frequent respiratory-related symptoms, including nose (odds ratio, OR 54.0; 95\% confidence interval, CI 21.6 to 134.8) and throat irritation (OR 4.3; CI, 2.2 to 8.5) compared to controls (non-exposed office workers), after adjusting for relevant confounders [34]. Kiec-Swierczynska et al. [52] captured information on respiratory symptoms (defined as wheezing and rales, chronic non-infection related cough, dyspnea) and other outcomes (ocular, nasal) during medical interviews among 93 Polish nail salon workers. Nail salon workers attributed several respiratory symptoms with exposure to nail dust, acrylic products, polish removers, disinfectants, and nail glues. The authors conducted a questionnaire among a larger sample of 145 nail salon workers, and, among these, $42 \%$ reported respiratory symptoms. Another Polish study [53] examined self-reported health status and work-related symptoms among 145 female nail salon workers occupationally exposed to VOCs with 152 population-based female controls. Nail salon workers experienced dyspnea, difficulty breathing, and regular/chronic coughing. Combined exposure to a VOC mixture did not modulate the hazard of occurrence of any symptoms assessed. The majority of recent studies in nail salons included in this scoping review were cross-sectional and respiratory symptoms were not always well defined. Additionally, some studies did not account for key confounders, including smoking $[52,54]$.

\section{Endocrine-Related Outcomes}

No articles on endocrine-related outcomes among hair or nail salon workers (e.g., thyroid, metabolic disease, diabetes) published in the last 5 years were identified. This reflects a critical data gap as chemicals in hair and nail care products include endocrine disrupting compounds (e.g., phthalates, placenta, parabens). Future studies should evaluate endocrine-related conditions and diseases among hair and nail salon workers in relation to EDC exposures.

\section{Current Gaps and Future Research Needs}

Most studies identified among hairdressers focused on Caucasian populations and a few on Middle Eastern and Asian hairdressers/salons. However, no published studies to date have assessed indoor environmental exposures and/or conducted biomonitoring among hairdressers who serve a predominantly Black clientele (i.e., African American, African, Afro Caribbean, Afro Latinas). A recent study [8••] detected 45 EDCs in 18 products used by Black women (e.g., hot oil treatments, root stimulators, hair lotions, and hair relaxers). Products tested contained between four and 30 of the EDCs measured; 11 of the products contained seven chemicals that are either prohibited for use in Europe or regulated under California Proposition 65 which requires businesses to provide warnings to Californians about significant exposures to chemicals that cause cancer, birth defects, or other reproductive harm [56]. Notably, $84 \%$ of the chemicals detected were not listed as ingredients. This evidence supports growing concerns that hairdressers using such products for personal use and/or on their clients may experience elevated exposures to VOCs, phthalates, and other chemicals that have been linked to adverse health effects. In addition to EDCs, some hair relaxers contain highly corrosive ingredients (e.g., lye) and other products may contain toxic solvents and adhesives. Hair loss, scalp lesions, and burns have been reported among hair relaxer users, which facilitate dermal chemical exposure [57]. Limited studies report associations between placentacontaining hair oils and other products with earlier age of menarche among African American adolescents and increased risk of uterine fibroids [57]. To our knowledge, no exposure or epidemiologic studies have been conducted among hairdressers predominantly serving a Black/ethnic clientele, highlighting the need for further research, particularly among hairdressers who may also use these products on themselves and experience an increased exposure burden. A combination of biomonitoring, exposure, and epidemiologic studies are urgently needed in this population, as disparate exposures are plausible. Research is also needed on ingredients in salon products to better understand their potential health impacts and to design culturally appropriate measures to reduce exposures and minimize health risks in this population. Additionally, while this review focused on select health endpoints, other health risks may be prevalent as a result of chemical exposures encountered in hair and nail salons, including cancer, skin conditions, neurotoxic effects, and immune disorders. 


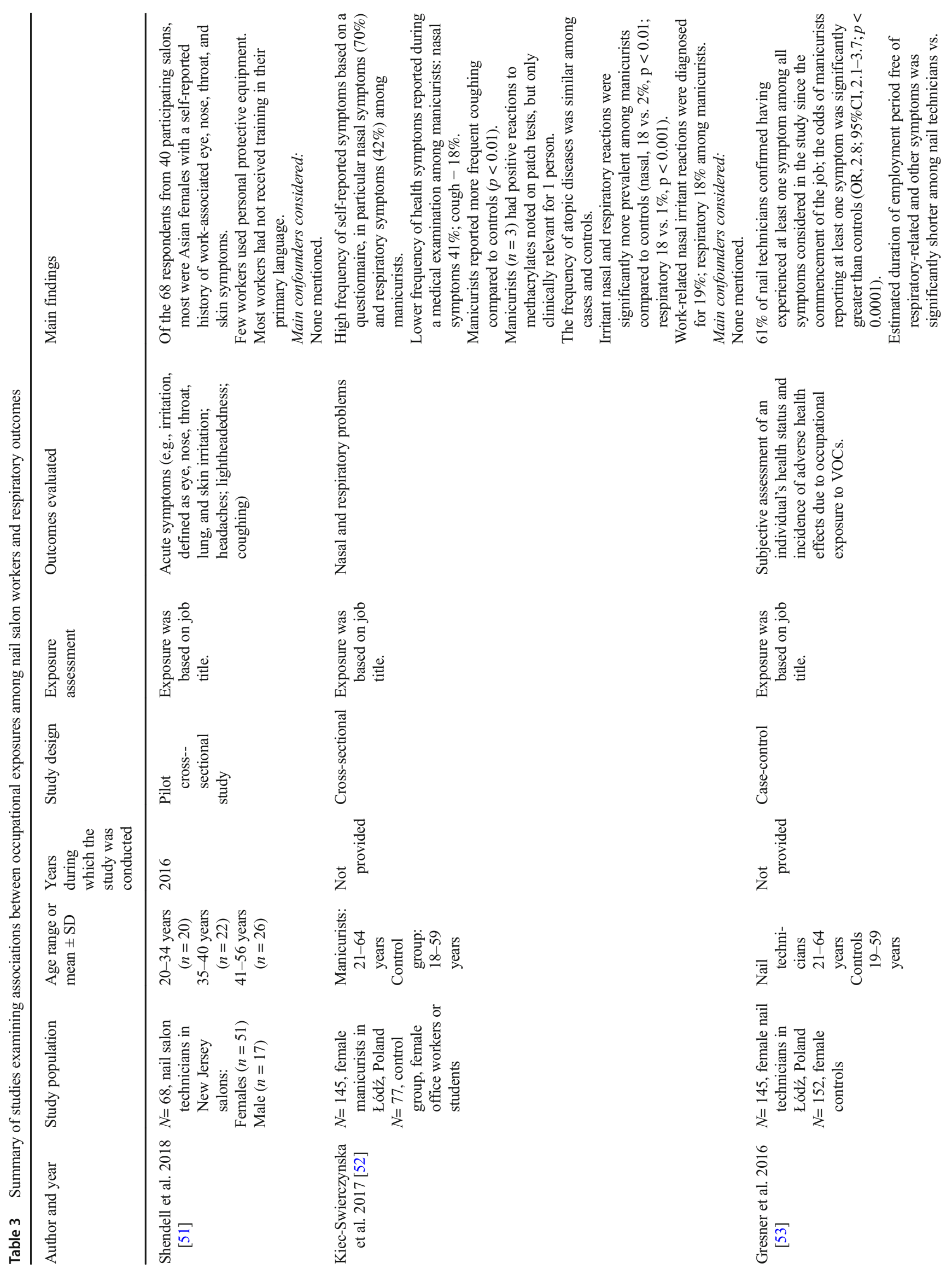




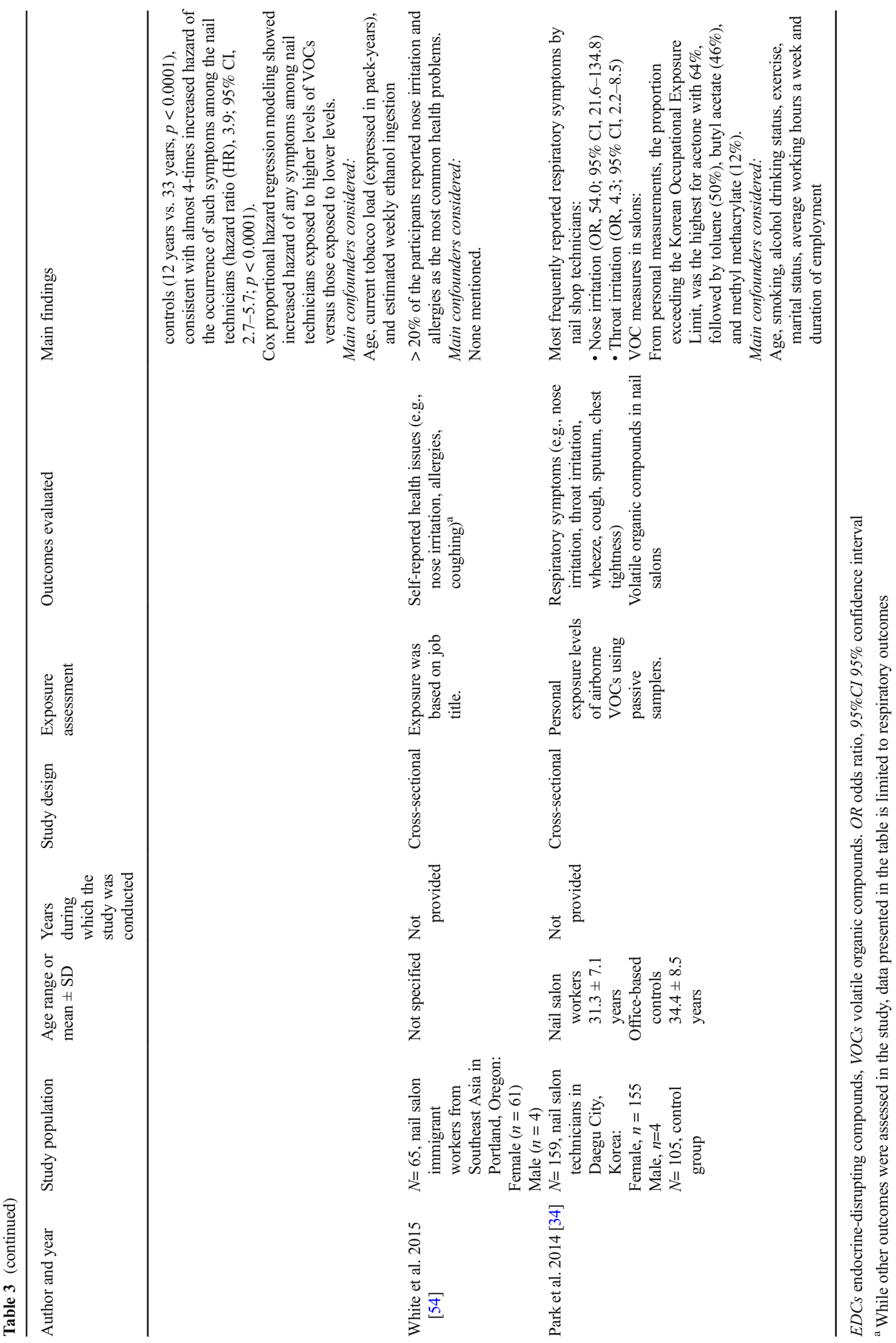


Currently, owners and workers in hair and nail salons have limited options for safer products and current regulations do not ensure worker health and safety. Guidelines and occupational standards are non-existent, outdated, or do not protect women of reproductive age. Recommendations to advance research on occupational health and workplace exposures among hair and nail salon workers include:

- Research on safe work practices and low to no-cost solutions to decrease chemical exposures in these settings

- Research on safer alternative products

- Characterization of exposures to chemicals via environmental and biological monitoring

- Non-targeted analysis to screen chemicals of potential concern and inform future epidemiologic studies

- Research on potential additive and synergistic effects of chemical exposures

- Epidemiologic studies to assess potential health effects of specific chemicals and mixtures of concern, including among hairdressers predominantly serving a Black clientele

- Research on the interplay between social factors and chemical exposures

In the U.S., labeling requirements for cosmetics and personal care products are limited because they are regulated as over-the-counter drugs by the Food and Drug Administration (FDA). The FDA requires ingredients to be listed proportionally to their content in the product but allows incidental ingredients and components in fragrances to be excluded from product ingredient lists (Fair Packaging and Labeling Act 1967; Federal Food, Drug, and Cosmetic Act 1938). This lack of transparency in labeling prevents workers and consumers from determining what chemicals they may be exposed to and what risks such exposures could pose. Moreover, while US federal occupational safety regulations and guidelines exist for some chemicals, these are outdated and may not be protective of this population. Occupational safety regulations in these settings are often promulgated by state cosmetology boards, which can vary by state, lack enforcement capacity, and fail to adequately address toxic chemical exposures.

\section{Conclusions}

Hair and nail salon workers are exposed to many chemicals linked to adverse effects. While more research is needed in these settings, safe work practices such as the use of PPE, proper ventilation, and using less harmful alternatives, if available, could help ameliorate exposures and lessen the risk of long-term health effects. Reducing salon exposures will require stakeholder involvement, including product manufacturers and government agencies, as the sole burden of safety should not fall on workers. Limited multipronged approaches to develop safer salons have achieved promising results [58, 59], and consumer demand for less-toxic beauty products has shown that such reformulations are marketable. While additional exposure and epidemiologic studies are warranted, improving air quality in salons and development of safer products is paramount to strengthen occupational health and safety among hair and nail salon workers.

Authors' Contributions LQA and AP conceived and designed the study. NT conducted the literature search with input from primary authors regarding initial key terms. MD generated the summary tables. LKK helped identify articles for inclusion in the manuscript. The manuscript was written with input from all the authors.

\section{Compliance with Ethical Standards}

Conflict of Interest The authors declare that they have no conflict of interest.

Human and Animal Rights and Informed Consent This article does not contain any studies with human or animal subjects performed by any of the authors.

\section{References}

Papers of particular interest, published recently, have been highlighted as:

- Of importance

•. Of major importance

1. U.S. Department of Labor. May 2018 national occupational employment and wage estimates [Internet]. [cited 2019 May 31]. Available from: https://www.bls.gov/cps/cpsaat11.htm.

2. Switalski E. Salon workers rising [Internet]. Women's voices for the earth. 2016 [cited 2019 May 31]. Available from: http://www. womensvoices.org/2016/04/14/salon-workers-rising/. This report summarizes some of the literature on the potential health effects that may arise from occupational exposures among hair and nail salon workers.

3. Chang C-J, Cheng S-F, Chang P-T, Tsai S-W. Indoor air quality in hairdressing salons in Taipei. Indoor Air. 2018;28:173-80. This is one of the most recent and more in-depth studies available on occupational indoor air exposures to VOCs and phthalates among hairdressers.

4. World Health Organization. Some aromatic amines, organic dyes, and related exposures [Internet]. World Health Organization, International Agency for Research on Cancer, editors. Lyon: IARC Press; 2010. Available from: https://www.ncbi.nlm.nih.gov/ books/NBK385419/. Accessed 25 Feb 2019

5.• Kolena B, Petrovičová I, Šidlovská M, Pilka T, Neuschlová M, Valentová I, et al. Occupational phthalate exposure and health outcomes among hairdressing apprentices. Hum Exp Toxicol. 2017;36:1100-12. This is the only study to date that has conducted biomonitoring of phthalates among hairdressers.

6. Skov T, Lynge E. Cancer risk and exposures to carcinogens in hairdressers. Skin Pharmacol Physiol. 1994;7:94-100. 
7. Takkouche B, Regueira-Méndez C, Montes-Martínez A. Risk of cancer among hairdressers and related workers: a meta-analysis. Int J Epidemiol. 2009;38:1512-31.

8.• Helm JS, Nishioka M, Brody JG, Rudel RA, Dodson RE. Measurement of endocrine disrupting and asthma-associated chemicals in hair products used by black women. Environ Res. 2018;165:448-58. This study quantified the presence of endocrine disrupting agents and several previously linked to respiratory outcomes in hair products marketed for Black women.

9. Stiel L, Adkins-Jackson PB, Clark P, Mitchell E, Montgomery S. A review of hair product use on breast cancer risk in African American women. Cancer Med. 2016;5:597-604.

10.• Dodson R, Nishioka M, Standley L, Perovich L, Brody J, Rudel R. Endocrine disruptors and asthma-associated chemicals in consumer products. Environ Health Perspect. 2012;120:935-43. This study quantified endocrine disruptors and asthma-related chemicals in a wide range of cosmetics, personal care products, cleaners, sunscreens, and vinyl products.

11. Colborn T, vom Saal FS, Soto AM. Developmental effects of endocrine-disrupting chemicals in wildlife and humans. Environ Health Perspect. 1993;101:378-84.

12. Tsigonia A, Lagoudi A, Chandrinou S, Linos A, Evlogias N, Alexopoulos EC. Indoor air in beauty salons and occupational health exposure of cosmetologists to chemical substances. Int $\mathrm{J}$ Environ Res Public Health. 2010;7:314-24.

13. van der Wal JF, Hoogeveen AW, Moons AMM, Wouda P. Investigation on the exposure of hairdressers to chemical agents. Environ Int. 1997;23:433-9.

14. Ronda E, Hollund BE, Moen BE. Airborne exposure to chemical substances in hairdresser salons. Environ Monit Assess. 2009;153: 83-93.

15. Nilsson PT, Marini S, Wierzbicka A, Karedal M, Blomgren E, Nielsen J, et al. Characterization of hairdresser exposure to airborne particles during hair bleaching. Ann Occup Hyg. 2016;60:90-100.

16. Kreiss K, Esfahani RS, Antao VCS, Odencrantz J, Lezotte DC, Hoffman RE. Risk factors for asthma among cosmetology professionals in Colorado. J Occup Environ Med. 2006;48:1062-9.

17. Quach T, Gunier R, Tran A, Von Behren J, Doan-Billings P-A, Nguyen K-D, et al. Characterizing workplace exposures in Vietnamese women working in California nail salons. Am J Public Health. 2011;101(Suppl 1):S271-6.

18. Gallicchio L, Miller SR, Greene T, Zacur H, Flaws JA. Adverse health outcomes among cosmetologists and noncosmetologists in the reproductive outcomes of salon employees (ROSE) study. J Toxicol Environ Health A. 2011;74:52-61. This study examined adverse effects, including those related to cardiovascular, respiratory, and skin problems, among cosmetologists and compared data to women of the same age in other occupations.

19. Centre for Reviews and Dissemination. Systematic reviews: CRD's guidance for undertaking reviews in health care [Internet]. 2009 [cited 2019 Apr 1]. Available from: https://www.york.ac.uk/crd/ guidance/.

20. Cochrane Collaboration. Cochrane handbook for systematic reviews of interventions [Internet]. In: Higgins JPT, Green S, editors. Chichester, England; Wiley-Blackwell; 2008 [cited 2019 Apr 1]. Available from: http://handbook-5-1.cochrane.org/.

21. Khan KS, Kunz R, Kleijnen J, Antes G. Systematic reviews to support evidence-based medicine: how to review and apply findings of healthcare research. London: Royal Society of Medicine Press; 2003.

22. Bramer WM, Rethlefsen ML, Mast F, Kleijnen J. Evaluation of a new method for librarian-mediated literature searches for systematic reviews. Res Synth Methods. 2018;9:510-20.

23. McGowan J, Sampson M, Salzwedel DM, Cogo E, Foerster V, Lefebvre C. PRESS peer review of electronic search strategies: 2015 guideline statement. J Clin Epidemiol. 2016;75:40-6.
24. Moher D, Liberati A, Tetzlaff J, Altman DG. Preferred reporting items for systematic reviews and meta-analyses: the PRISMA statement. Int J Surg. 2010;8:336-41.

25. Saraga DE, Volanis L, Maggos T, Vasilakos C, Bairachtari K, Helmis CG. Workplace personal exposure to respirable PM fraction: a study in sixteen indoor environments. Atmos Pollut Res. 2014;5:431-7.

26. Subedi B, Sullivan KD, Dhungana B. Phthalate and non-phthalate plasticizers in indoor dust from childcare facilities, salons, and homes across the USA. Environ Pollut. 2017;230:701-8.

27. Nemer M, Sikkeland LIB, Kasem M, Kristensen P, Nijem K, Bjertness E, et al. Airway inflammation and ammonia exposure among female Palestinian hairdressers: a cross-sectional study. Occup Environ Med. 2015;72:428-34.

28. Lowell Center for Sustainable Production. Phthalates and their alternatives: health and environmental concerns [internet]. Lowell: University of Massachusetts; 2011. Available from: http://ec. europa.eu/environment/aarhus/pdf/35/Annex 11 report from Lowell_Center.pdf. Accessed 25 Feb 2019

29. Fiume MM, Heldreth B, Eldreth H, Bergfeld WF, Belsito DV, Hill RA, et al. Final report of the cosmetic ingredient review expert panel on the safety assessment of dicarboxylic acids, salts, and esters. Int J Toxicol. 2012;31:5S-76S.

30. Porras SP, Hartonen M, Ylinen K, Tornaeus J, Tuomi T, Santonen T. Environmental and occupational exposure to resorcinol in Finland. Toxicol Lett. 2018;298:125-33.

31. Goldin LJ, Ansher L, Berlin A, Cheng J, Kanopkin D, Khazan A, et al. Indoor air quality survey of nail salons in Boston. J Immigr Minor Health. 2014;16:508-14.

32. Gresner P, Swiercz R, Krol MB, Twardowska E, Gromadzinska J, WasowiczW. Does the low-level occupational exposure to volatile organic compounds alter the seasonal variation of selected markers of oxidative stress? A case-control study in nail technicians. J Occup Med Toxicol. 2016. https://doi.org/10.1186/s12995-0160125-6.

33. Lamplugh A, Harries M, Xiang F, Trinh J, Hecobian A, Montoya LD. Occupational exposure to volatile organic compounds and health risks in Colorado nail salons. Environ Pollut. 2019;249: 518-26.

34. Park S, Gwak S, Choi S. Assessment of occupational symptoms and chemical exposures for nail salon technicians in Daegu City, Korea. J Prev Med Public Health. 2014;47:169-76.

35. Pavilonis B, Roelofs C, Blair C. Assessing indoor air quality in New York City nail salons. J Occup Environ Hyg. 2018;15:422-9.

36. Zhong L, Batterman S, Milando CW. VOC sources and exposures in nail salons: a pilot study in Michigan, USA. Int Arch Occup Environ Health. 2019;92:141-53.

37. Omokhodion FO, Roberts OA, Onadeko MO, Beach JR, Cherry N, Burstyn I. Social, obstetric and environmental determinants of low Apgar score among infants born in four selected hospitals in Ibadan, Nigeria. J Obstet Gynaecol. 2018;38:454-60.

38. Park C, Kang MY, Kim D, Park J, Eom H, Kim EA. Prevalence of abortion and adverse pregnancy outcomes among working women in Korea: a cross-sectional study. PLoS One. 2017;12:e0182341.

39. Quach T, Von Behren J, Goldberg D, Layefsky M, Reynolds P. Adverse birth outcomes and maternal complications in licensed cosmetologists and manicurists in California. Int Arch Occup Environ Health. 2015;88:823-33.

40. Kalfa N, Paris F, Philibert P, Orsini M, Broussous S, FauconnetServant $\mathrm{N}$, et al. Is hypospadias associated with prenatal exposure to endocrine disruptors? A French collaborative controlled study of a cohort of 300 consecutive children without genetic defect. Eur Urol. 2015;68:1023-30.

41. U.S. Department of Labor. Employment characteristics of families 2018 [Internet]. 2019 [cited 2019 Jun 11]. Available from: https:// www.bls.gov/news.release/pdf/famee.pdf 
42. Greenland S, Gustafson P. Accounting for independent nondifferential misclassification does not increase certainty that an observed association is in the correct direction. Am J Epidemiol. 2006;164:63-8.

43. Foss-Skiftesvik MH, Winther L, Johnsen CR, Sosted H, Mosbech $\mathrm{HF}$, Zachariae $\mathrm{C}$, et al. High occurrence of rhinitis symptoms in hairdressing apprentices. Int Forum Allergy Rhinol. 2017;7:43-9.

44. Foss-Skiftesvik MH, Winther L, Johnsen CR, Zachariae C, Johansen JD. Incidence of skin and respiratory diseases among Danish hairdressing apprentices. Contact Dermatitis. 2017;76: 160-6.

45. Hassan O, Bayomy H. Occupational respiratory and musculoskeletal symptoms among Egyptian female hairdressers. J Community Health. 2015;40:670-9.

46. Lysdal SH, Mosbech H, Johansen JD, Søsted H. Asthma and respiratory symptoms among hairdressers in Denmark: results from a register based questionnaire study. Am J Ind Med. 2014;57:136876.

47. Hansell A, Ghosh RE, Poole S, Zock JP, Weatherall M, Vermeulen $\mathrm{R}$, et al. Occupational risk factors for chronic respiratory disease in a New Zealand population using lifetime occupational history. J Occup Environ Med. 2014;56:270-80.

48. Diab KK, Jonsson BA, Axmon A, Nielsen J. Work-related airway symptoms, nasal reactivity and health-related quality of life in female hairdressers: a follow-up study during exposure. Int Arch Occup Environ Health. 2014;87:61-71.

49. Nemer M, Kristensen P, Nijem K, Bjertness E, Skare O, Skogstad $\mathrm{M}$. Lung function and respiratory symptoms among female hairdressers in Palestine: a 5-year prospective study. BMJ Open. 2015;5:e007857.

50. Toru U, Arbak PM, Suner KO, Yavuz O, Karatas N. Relationship between respiratory tract complaints, functional status, and smoking in hairdressers, auto painters, and carpenters. Sci World J. 2014;2014:802705.

51. Shendell DG, Graber JM, Milich LJ, Pratt ME. Assessing acute symptoms related to occupational exposures among nail salon technicians. J Occup Environ Med. 2018;60:343-9.
52. Kiec-Swierczynska M, Swierczynska-Machura D, ChomiczewskaSkora D, Krecisz B, Walusiak-Skorupa J. Screening survey of ocular, nasal, respiratory and skin symptoms in manicurists in Poland. Int J Occup Med Environ Health. 2017;30:887-96.

53. Gresner P, Swiercz R, Wasowicz W, Gromadzinska J. Faster health deterioration among nail technicians occupationally exposed to low levels of volatile organic compounds. Int J Occup Med Environ Health. 2017;30:469-83.

54. White H, Khan K, Lau C, Leung H, Montgomery D, Rohlman DS. Identifying health and safety concerns in Southeast Asian immigrant nail salon workers. Arch Environ Occup Health. 2015;70: 196-203.

55. Centers for Disease Control and Prevention. Phthalates factsheet [Internet]. National Biomonitoring Program, CDC. 2019 [cited 2019 Jun 4]. Available from: https://www.cdc.gov/biomonitoring/ Phthalates FactSheet.html.

56. Office of Environmental Health Hazard Assessment. Proposition 65 [Internet]. n.d. Available from: https://oehha.ca.gov/ proposition-65. Accessed 25 Feb 2019

57. Wise LA, Palmer JR, Reich D, Cozier YC, Rosenberg L. Hair relaxer use and risk of uterine leiomyomata in African-American women. Am J Epidemiol. 2012;175:432-40.

58. Quach T, Liou J, Fu L, Mendiratta A, Tong M, Reynolds P. Developing a proactive research agenda to advance nail salon worker health, safety, and rights. Prog Community Health Partnersh. 2012;6:75-82.

59. California Healthy Nail Salon Collaborative. About us [Internet]. [cited 2019 Jun 4]. Available from: https://cahealthynailsalons.org/ about-us.

Publisher's Note Springer Nature remains neutral with regard to jurisdictional claims in published maps and institutional affiliations. 